\title{
QUALITY LEADERSHIP WHEN REGULATORY STANDARDS ARE FORTHCOMING*
}

\begin{abstract}
Stefan Lutz, $\uparrow$ Thomas P. Lyon $\$$ and John W. Maxwell
In many markets, governments set minimum quality standards while some sellers compete on the basis of quality by exceeding them. Such quality leadership strategies often win public acclaim, especially when they involve environmental attributes. Using a duopoly model of vertical product differentiation, we show that if the high-quality firm can commit to a quality level before regulations are promulgated, it induces the regulator to weaken standards, and welfare falls. Our results raise doubts about the social benefits of corporate self-regulation, and highlight the dangers of lengthy delays between legislative mandates for new regulations and their implementation.
\end{abstract}

\section{INTRODUCTION}

SINCE THE 1960s INDUSTRY has gone from vigorously resisting regulation of health, safety and the environment to pro-actively managing its impacts in these areas. ${ }^{1}$ Corporate moves in this direction have gained almost universal applause from outside observers, especially in the area of environmental protection. ${ }^{2}$ Two primary motives for the shift toward corporate leadership in these areas have been identified: attracting high-

\footnotetext{
* Lutz acknowledges financial support by DFG LU 633/2-1. Maxwell acknowledges financial support from the Kelley School. This research was initiated while Lyon was a visitor at the Zentrum für Europäische Integrationforschung (ZEI), Universität Bonn. We thank Mike Baye, Joe Farrell, Richard Newell, Mike Toman, three anonymous referees, and participants at the American Economic Association meetings for comments.

$\uparrow$ Authors' affiliation: Purdue University, Department of Economics, West Lafayette, IN 47907-1310, USA.

email:lutzs@mgmt.purdue.edu

$\downarrow$ Kelley School of Business, Indiana University, Bloomington, IN 47405-1710, USA. email: tlyon@indiana.edu

$\S$ Kelley School of Business, Indiana University, Bloomington, IN 47405-1710, USA. email:jwmax@indiana.edu

${ }^{1}$ For an interesting account of this shift within the environmental context, see Hoffman [1997].

${ }^{2}$ A good example is ARCO's introduction of reformulated gasolines, a strategy which has been written up as a case study by Schaefer [1993] for use in Stanford University's MBA program. The new fuels garnered very favorable treatment in the press, and were dubbed the 'Product of the Year' by Fortune magazine. According to Piasecki [1992], in the Los Angeles Times, the firm's 'return on stockholder equity in 1991 was $29.3 \%$, making ARCO the best performer in the oil industry. Its success is due to an unprecedented new-product development strategy, an environmental strategy. ARCO anticipates environmental regulations to gain significant market advantages.'
}

๑ Blackwell Publishers Ltd. 2000, 108 Cowley Road, Oxford OX4 1JF, UK, and 350 Main Street, Malden, MA 02148, USA 
income consumers who are willing to pay a premium for safer or more environmentally-friendly products, and preempting mandatory government regulations. A small but growing body of theoretical economic research suggests that each of these motives individually leads to welfare-enhancing corporate actions. ${ }^{3}$ This paper is designed to probe the robustness of these sanguine conclusions about the social benefits of corporate self-regulation.

We study the effects of corporate leadership in the health, safety and environmental areas when future regulations cannot be preempted, but can be influenced by corporate actions. We formally model the idea of shaping future regulations by allowing a high-quality firm to make a sunk investment in a technology that exceeds both current and anticipated government quality standards. This action is followed by the setting of a new minimum quality standard by government, which aims to maximize social welfare. After the standard is set, firms not presently meeting the standard comply with it, and all firms compete in the product market. Our key result is that by strategically exceeding anticipated standards by a limited amount, the high-quality firm can influence the government to set lower standards, thereby leading to a lower level of social welfare than would be achieved under the 'government as leader' scenario. Our analysis thus calls into question the benefits of pro-active corporate quality leadership.

The key difference between our model and earlier models of minimum quality standards (see e.g. Ronnen [1991] and Arora and Gangopadhyay [1995]) is the timing of firm and government actions. Previous work has examined how both high- and low-quality firms react to the imposition of minimum quality standards; in these models, the government is the first mover, and the firms are followers. Our model, in contrast, grants the leadership role to a high-quality firm. Thus, some discussion of the timing of our model is in order.

The notion that corporate actions influence government decisions is commonplace in the study of political economy. Indeed, examples of such influence on environmental, health and safety regulation are legion. ${ }^{4}$ In the US, interest group influence is virtually guaranteed by the Administrative Procedures Act of 1946, which requires regulators to give notice to all interested parties before promulgating new regulations, and requires that parties be allowed to provide commentary to regulatory authorities on proposed rules. More importantly for our purposes, it is often the case that Congress mandates the imposition of new health, safety or environ-

\footnotetext{
${ }^{3}$ Arora and Gangopadhyay [1995] present a model in which firms over-comply with regulations in order to attract high-income consumers. Hansen [1999], Segerson and Miceli [1998], and Maxwell et al. [2000] study self-regulation as a means of preempting mandatory regulations. Lyon and Maxwell [2000] offer a survey of the growing literature in this area.

${ }^{4}$ See Stigler [1988] for a collection of political economic studies, many of which focus on the causes and consequences of government regulations. 
mental regulations, but delegates the technical details - with considerable delay - to a regulatory agency such as the Environmental Protection Agency (EPA) or the Department of Energy (DOE).

An interesting example is the National Appliance Energy Conservation Act of 1987 (NAECA), which required that minimum energy efficiency standards be met by January 1, 1990, for room air conditioners and gas water heaters. The specifics of the standards were delegated to the Department of Energy, and determined only after consultations with industry members. The manufacturers did not wait until the deadline to meet the standards, but instead began positioning themselves in advance. Newell et al. [1998] provide a detailed empirical analysis of the changes in energy efficiency for these appliances over the period 1958-1993. For example, in 1958 the average room air conditioner produced 5.9 British thermal units/hour/watt and the standard deviation across units was 1.0; by 1993 the average had risen to 9.0 with a standard deviation of only 0.6 . Clearly there is a menu of products that vary in quality, with the upper end exceeding the minimum standard by a significant amount. The authors estimate that for room air conditioners $24 \%$ of the improvement in energy efficiency since 1973 can be attributed to the standards, while for gas water heaters $69 \%$ of the improvement was due to standards. Interestingly, the technological frontier did not appear to shift outward in the wake of the standards; instead 'the primary effect was the elimination of the distribution's lower tail'. Apparently high-quality firms committed in advance to certain technologies and did not re-adjust their products after the government set its standards.

A timely example of considerable delay between the passage of laws and the promulgation of standards involves the Clean Air Act Amendments of 1990. This Act identified a group of 189 toxic chemicals to be subjected to National Emission Standards for Hazardous Air Pollutants (NESHAP) by the year 2000. The decade between the announcement of the new standards and their actual implementation gave firms ample opportunity to position themselves in a way that would favorably influence the standards. In fact, many firms have already made investments that have substantially reduced their emissions of various toxics identified in the Clean Air Act amendments. ${ }^{6}$ Whether these actions were specifically motivated by a desire to influence the ultimate standards, or were purely anticipatory, is an interesting empirical question which would probably be best tackled through a case study of the development of the ultimate standards.

In the global arena, high-quality firms may work with their domestic

\footnotetext{
${ }^{5}$ Newell et al. [1998], footnote 35.

${ }^{6}$ See Khanna and Damon [1999] for further discussion of the Clean Air Act's NESHAP and some empirical evidence indicating that firms have been reducing their emissions of toxic pollutants prior to the imposition of forthcoming standards. 
governments to require the use of particular technologies, with the goal of influencing international standards. An interesting example is provided by the European Union (EU) Commission's 1985 decision regarding the stringency of automobile emissions standards. In 1984, concerns about acid rain led the Federal Republic of Germany-with the support of the German automotive industry - to adopt a clean-car regulation. Because the regulation applied to all automobiles sold in Germany, it was labelled a barrier to trade and quickly became a European issue. When the EU Commission proposed $\mathrm{NO}_{\mathrm{x}}$ standards later in 1984, producers and governments quickly fell into two groups. The German-led group pressed for standards that dictated best available control technologies (which effectively meant the use of three-way catalytic converters), while the second group, lead by France and French producers, argued for further study of potentially better 'clean engine' technologies. While the EU Commission deliberated, the German government, with the backing of its automakers, adopted fuel emission standards that essentially dictated the use of the three-way catalytic converter technology. ${ }^{7}$ Two months later the EU Commission enacted standards that lead to the adoption of catalytic technology for the EU. The German government's standards allowed German manufacturers to commit to a technology that improved on the emissions of vehicles they currently sold in Europe, and influenced the Commission to raise the standards facing all manufacturers in Europe. However, the German move may have also resulted in emissions standards that were lower than those that might have been set had all technological options been studied. Lévêque and Nadaï [1995] note that there was potential for better technologies, including the coupling of clean engines and catalytic converters. The emission standards set by the EU Commission were not strict enough to force this technology, however, and French producers abandoned (at least temporarily) active research on the clean engine to focus on equipping their existing engines with the German catalytic converter technology.

Economic research on how technology-based standards are crafted indicates that the actions of quality leaders in an industry can indeed affect the standards set by regulators. For example, the Clean Water Act of 1972 and its 1977 amendments mandated, among other things, that the EPA establish standards for emissions of organic chemicals. The EPA finally issued proposed effluent guidelines in March 1983, which 'were established by averaging the effluent quality achieved by existing plants that were selected as being well controlled'. ${ }^{8}$ Obviously standards would have been

\footnotetext{
${ }^{7}$ Of course, differences in fuel efficiency and other design features meant that some cars remained cleaner than others despite the new minimum quality standards.

${ }^{8}$ See Caulkins and Sessions [1997] for further details. A careful reading of Caulkins and Sessions indicates that approximately 11 out of 300 plants were deemed to be well controlled see pp. 95-105.

(๑) Blackwell Publishers Ltd. 2000
} 
weaker if industry quality leaders had installed poorer control techniques. ${ }^{9}$ The deliberation process explicitly weighed economic considerations, including effects on firm profitability and potential employment losses from plant closures. In fact, due to economic considerations, neither the 'Best Practicable Technology' (BPT) standards nor the more stringent 'Best Available Technology' (BAT) standards actually required the use of the most effective abatement technologies on the market. ${ }^{10}$

The foregoing examples show that firms may have an extended period of advance warning before the imposition of new standards, and that the products and production processes firms choose affect the standards chosen by regulators. Our analysis, by allowing quality leaders to influence future standards, leads to interesting results which call into question the universal applause for pro-active corporate quality leadership. Specifically, we find that the leader's quality choice will be lower than it would have been had the government set a minimum quality standard (MQS) first. By strategically sinking the costs of a technology that exceeds anticipated government standards by a limited amount, the leader influences the government to set a lower MQS. This lower MQS means that the leader's action leads to a lower level of social welfare than would be achieved under the 'government as leader' scenario.

An important assumption in our analysis is that the high-quality firm can commit to a given level of quality. ${ }^{11}$ For this commitment to be credible, the firm must face a fixed cost of changing quality levels large enough to outweigh any additional benefits from adjusting quality after standards are imposed. We thus have in mind a 'putty/clay' technology, where the firm has a continuum of quality choices ex ante, but is effectively locked into a single quality ex post. ${ }^{12}$ This is particularly plausible when improving quality requires the firm to retool its production process, as is often the case when firms undertake a 'pollution prevention' approach to abatement. ${ }^{13}$ For reasons of both theory and practice, we assume that the low-quality firm cannot pre-commit to a quality level. From a modeling perspective, if all firms can make a binding commitment before the regulator steps in, then the regulator is rendered powerless, making impossible

\footnotetext{
${ }^{9}$ Here small numbers of type $\mathrm{H}$ firms matter, since if there are many then none has much impact on the standard.

${ }^{10}$ The discussion in this paragraph is drawn from Caulkins and Sessions [1997].

${ }^{11}$ This is a standard assumption in multi-stage models of product differentiation; see, e.g. Lehmann-Grube [1997].

${ }^{12}$ In some cases, regulation may force all firms to change their production processes, e.g. by imposing 'technology-forcing' standards that require development of innovative new technologies. Such cases are interesting, and voluntary actions in these cases may involve a different set of incentives; however such a model is beyond the scope of the present paper.

${ }^{13}$ In future work, it may be of interest to explore in depth the leader's choice between technologies that offer different levels of sunk costs, as in Williamson [1985], chapter 7. 
any analysis of the interaction between regulation and corporate strategy. ${ }^{14}$ From a practical perspective, casual empiricism strongly suggests that regulations typically do not simply ratify the lowest quality currently offered by any firm; instead they have demonstrable effects on low-quality firms, forcing them to improve their products. ${ }^{15}$

The rest of the paper is structured as follows. Section II presents our results in general form, deriving them from an assumed set of sufficient conditions. Section III demonstrates that our sufficient conditions hold in a specific model of vertical product differentiation. Section IV discusses the results and concludes.

\section{A GENERAL MODEL}

Several authors have shown how minimum quality standards can raise welfare when products are vertically differentiated and buyers fully internalize the benefits of quality. ${ }^{16}$ The basic notion is that by forcing up the lowest quality level on offer in the market, the regulator can intensify price competition to the benefit of consumers. The best response of the high quality firm is to raise its own quality level in an attempt to reduce price competition. It is not optimal, however, for the high quality firm to fully offset the rise in the MQS. Thus, prices fall and qualities rise as a result of the MQS. ${ }^{17}$

\footnotetext{
${ }^{14}$ Interesting issues arise if all firms can pre-commit to a minimum quality level, but regulators can later require additional improvement. Maxwell et al. [2000] examine this possibility for the case of homogeneous firms, and characterize the conditions under which the emergence of mandatory government regulations may be preempted altogether. An interesting topic for further research may be a model that combines our model with that of Maxwell et al. [2000], allowing for the possibility of preemption, but also for the sorts of regulatory manipulation we describe here.

${ }^{15}$ This was the case for the Clean Water Act, as discussed above, which set a standard based on 'well controlled' plants, not on the basis of the most poorly controlled plants. Similarly, appliance standards for air conditioners and gas water heaters had significant effects on the low-quality end of the market, as discussed above. In like manner, Linneman [1980] reports that flammability standards for mattresses forced low-quality manufacturers to eliminate the use of untreated cotton and to include a layer of polyurethane in their products, requiring a significant retooling of their production processes.

${ }^{16}$ See, for example, Ronnen [1991], Boom [1995], Crampes and Hollander [1995], and Arora and Gangopadhyay [1995].

${ }^{17}$ Linneman's [1980] study of the 1973 mattress flammability standard found that the price of the highest quality mattresses did indeed fall after the imposition of the standard. He notes [p. 454] that the standard had greatest impact on small producers, as 'most large producers had adopted the requisite production technology' already. Linneman did not examine formally changes in the vector of qualities on offer before and after the standard, but he does note [fn. 24, p. 459] that even after the imposition of the standard, it was not true that 'all passing mattresses are of the same quality with respect to flammability'.
} 
When the benefits of quality are not fully internalized by consumers, concerns about externalities must also be taken into account. ${ }^{18}$ If one considers health, safety and a clean environment as aspects of product quality, then minimum quality standards can be thought of as a way to mitigate externalities. Our model is general enough to accommodate both externalities and insufficient price competition as motivations for government to promulgate minimum quality standards.

In this section, we present our argument in general form. Two firms compete on the basis of both (vertical) quality and price. Since product differentiation relaxes price competition, even firms with identical cost functions will offer distinct qualities in equilibrium. We refer to the highquality firm as firm $\mathrm{H}$ and the low-quality firm as firm $\mathrm{L}$. The regulator may set an MQS either to increase price competition or to reduce the external impacts of production. As a benchmark, we analyze the case where the regulator and the high-quality firm choose qualities simultaneously in the first stage of the game. This benchmark provides a convenient point from which to approach the timing of quality standards, with either the high-quality firm or the regulator acting as the first mover. First, we characterize the equilibrium when the regulator leads, setting a binding minimum quality level for firm $\mathrm{L}$, with firm $\mathrm{H}$ making its quality choice after the regulation is set. To this equilibrium we compare the equilibrium in which high quality firm $\mathrm{H}$ commits to its quality level before the regulator promulgates a standard. ${ }^{19}$

Throughout the paper we use the following notation. Quality levels are denoted by $s_{i} i=\{H, L\}$, where $H$ denotes the high-quality firm and $L$ denotes the low-quality firm. Similarly, profits are denoted by $\pi_{i}\left(s_{H}, s_{L}\right)$ $i=\{H, L\}$. External costs, e.g. environmental damages due to pollution, are represented by $D\left(s_{H}, s_{L}\right)$, and consumer surplus from the purchase of the firms' products is given by $C S\left(s_{H}, s_{L}\right)$. Social welfare, assumed to be the regulator's objective, is given by $W\left(s_{H}, s_{L}\right)=\pi_{H}\left(s_{H}, s_{L}\right)+\pi_{L}\left(s_{H}, s_{L}\right)+$ $C S\left(s_{H}, s_{L}\right)-D\left(s_{H}, s_{L}\right)$. We define the $2 \times 1$ vector of qualities $\boldsymbol{s}^{*}=$ $\operatorname{argmax} W\left(s_{H}, s_{L}\right)$ to be the unconstrained welfare-maximum. Choice variables without subscripts denote $2 \times 1$ vectors, and are in bold type. Inequalities written in vector form apply to all arguments of the vector.

\footnotetext{
${ }^{18}$ For an excellent textbook treatment of externalities from a regulatory perspective, see Viscusi et al. [1995], Section III.

${ }^{19}$ We have not modeled explicitly solvency constraints for the firms; these constraints will not be binding if welfare is sufficiently concave in quality. Positive profits can be assured through a number of means. For example, the regulator might weight profits more heavily than other factors in its objective function, the firms might start the game with large positive quality levels, the firms might operate in multiple markets with economies of scope and/or scale, or the regulator might, if necessary, intervene to ensure that firms remain solvent after standards are imposed. Even if solvency constraints were modeled explicitly, the qualitative nature of our results would remain: the high-quality firm would prefer to commit to a lower level of quality than it would choose if the regulator moved first.
} 


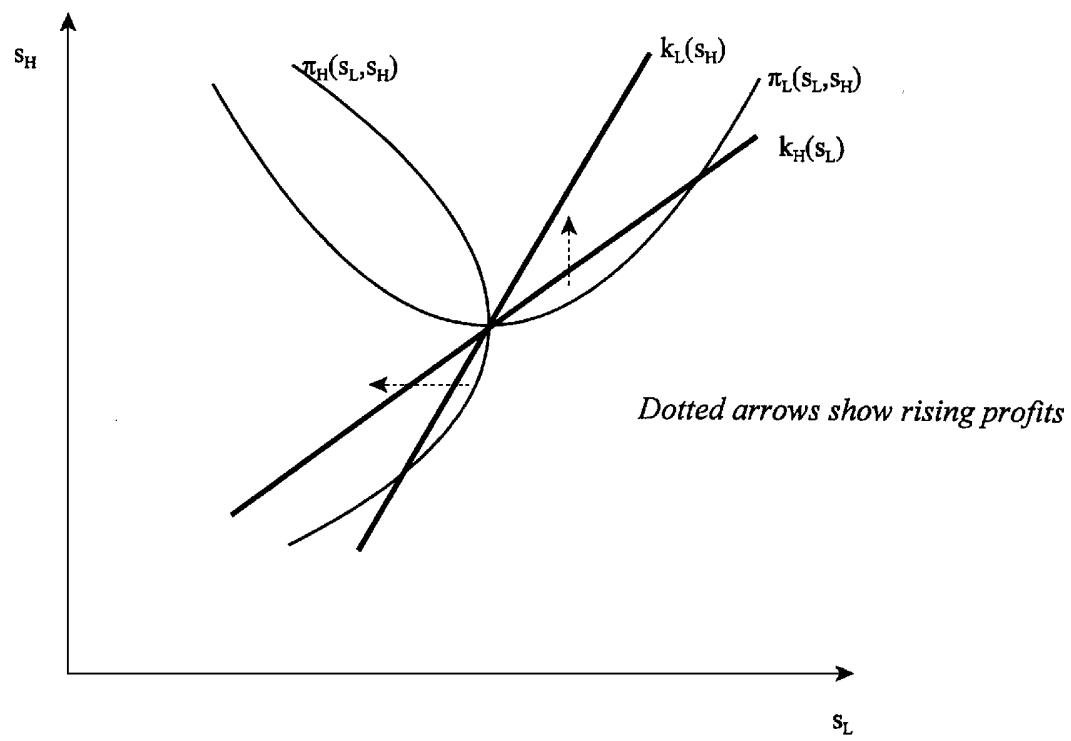

Figure 1

Quality Strategic Complements

II(i). Assumptions

We begin our formal analysis by presenting a set of assumptions sufficient to generate our results:

1. Profit functions $\pi_{i}\left(s_{H}, s_{L}\right) i=\{H, L\}$ and social welfare $W\left(s_{H}, s_{L}\right)$ are globally concave. In addition, $\partial^{2} \pi_{i} / \partial s_{i} \partial s_{j}>0 i=\{H, L\}, \partial^{2} W / \partial s_{H} \partial s_{L}>0$, and $\partial \pi_{H} / \partial s_{L}<0$.

2. The regulator sets a minimum quality standard. The high-quality firm chooses to exceed it, but the low-quality firm does not. In the simultaneous-move game between the standard-setting regulator and the high-quality firm, there exists a unique Nash equilibrium in qualities, $\boldsymbol{s}^{N}=\left(s_{L}^{N}, s_{H}^{N}\right)$.

3. $s^{*}>s^{N}$.

Note that assumptions 1 and 2 together ensure that quality choices are strategic complements, so reaction curves are upward sloping. This is illustrated for the two firms in Figure 1, but is also true of the regulator's reaction curve $v\left(s_{H}\right)$ as shown in Figure 2. Assumption 3 states that the regulator prefers a higher level of quality than is provided in the Nash equilibrium. ${ }^{20}$

\footnotetext{
${ }^{20}$ Note that an MQS is useless if the regulator desires a lower quality level than is provided at the Nash equilibrium.

๑) Blackwell Publishers Ltd. 2000.
} 
II(ii). Results in the General Case

We begin our formal analysis by comparing the benchmark simultaneousmove equilibrium between the regulator and the high-quality firm to the equilibrium of the game in which the regulator sets the MQS before firm $\mathrm{H}$ chooses its quality level. Our findings are characterized in proposition 1.

Proposition 1. Compared to the benchmark equilibrium in the simultaneous-move game between the regulator and the high-quality firm, the equilibrium in which the MQS is determined prior to the quality choice of the high-quality firm features higher quality levels for both firms, lower profits for the high-quality firm and a higher level of social welfare.

Proof. Let $k_{H}\left(s_{L}\right)$ be firm H's reaction curve. Assumptions 1 and 2 imply that the high quality firm's reaction function is upward sloping, i.e. $d k_{H} / d s_{L}>0$. At the Nash equilibrium, the regulator is on an indifference curve in $\left(s_{L}, s_{H}\right)$-space defined by the equation $W\left(s_{H}, s_{L}\right)=W^{N}$. The regulator-if granted commitment power-can improve welfare by moving away from the Nash equilibrium if the following expression is positive:

$$
\left.\frac{d W\left(k_{H}\left(s_{L}\right), s_{L}\right)}{d s_{L}}\right|_{s^{N}}=\left.\left.\frac{\partial W}{\partial s_{H}}\right|_{s^{N}} \frac{d k_{H}}{d s_{L}}\right|_{s^{N}}+\left.\frac{\partial W}{\partial S_{L}}\right|_{s^{N}} .
$$

Note that the last term is equal to zero at the Nash equilibrium, and recall that $d k_{H} / d s_{L}>0$. Hence the sign of the expression as a whole is equal to the sign of $\partial W / \partial s_{H}$. To sign this term, we totally differentiate the implicit function defining the regulator's indifference curve, $W\left(s_{H}, s_{L}\right)=W^{N}$, yielding

$$
\left.\frac{d s_{H}}{d s_{L}}\right|_{W=W^{N}}=\frac{-\partial W / \partial s_{L}}{\partial W / \partial s_{H}}
$$

Because $W$ is globally concave, level sets are convex. Assumption 3 ensures that in the neighborhood of the Nash equilibrium, the regulator's indifference curves are convex toward the origin. Hence, $d s_{H} / d s_{L}<(>) 0$ for points on $W^{N}$ just to the left (right) of $s^{N}$. Furthermore, $s_{L}^{N}$ is a best response and welfare is concave, so in the neighborhood of $\boldsymbol{s}^{N}, \partial W / \partial s_{L}>(<) 0$ for $s_{L}<(>) s_{L}^{N}$. Together, these observations imply that in the neighborhood of $\boldsymbol{s}^{N}, \partial W / \partial s_{H}>0$. Hence, the sign of $d W\left(k_{H}\left(s_{L}\right), s_{L}\right) / d s_{L}$ is positive and the regulator can improve welfare by increasing the MQS above the Nash equilibrium level and thereby inducing the high-quality firm to increase its quality as well.

Because the high-quality firm's indifference curves are convex toward the origin, it is immediate that movement outward along its reaction curve reduces the high-quality firm's profits. Thus we have established that the equilibrium in which the MQS is determined prior to the 
quality choice of the high-quality firm features higher quality levels for both firms, lower profits for the high-quality firm and a higher level of social welfare.

Q.E.D.

Proposition 1 shows that the regulator benefits from being able to move first, since it can thereby set a higher MQS, but the high-quality firm is worse off. The high-quality firm thus has incentives to try and prevent the regulator from exercising a first-mover advantage. In particular, we would like to know the optimal strategy for firm $\mathrm{H}$ to adopt if it anticipates an MQS will be imposed by the regulator. The following proposition characterizes the equilibrium if firm $\mathrm{H}$ chooses its quality level prior to the regulator's choice of the MQS.

Proposition 2. Compared to the benchmark case, if the high-quality firm can precommit to a quality level before minimum quality standards are promulgated, it will induce the regulator to set a weaker standard, and both firms will produce lower quality. While the high-quality firm's profits increase, welfare falls.

Proof. An argument similar to that used in the proof of Proposition 1 establishes that there exists a point $\boldsymbol{s}^{H}=\left(s_{L}^{H}, s_{H}^{H}\right)$ on the regulator's reaction curve such that $\boldsymbol{s}^{H}<\boldsymbol{s}^{N}$ with $\pi^{H}>\pi^{N}$. Assumption 3 ensures that social welfare increases moving outward along the regulator's reaction curve until the point $\boldsymbol{s}^{*}$ is reached; since $\boldsymbol{s}^{H}<\boldsymbol{s}^{N}<\boldsymbol{s}^{*}$, social welfare at $\boldsymbol{s}^{H}$ is strictly lower than at $\boldsymbol{s}^{*}$.

Q.E.D.

Proposition 2 shows that the high-quality firm benefits from having a first-mover position, and uses its position to induce lower qualities. In particular, it commits to a lower quality level than would emerge if the regulator moved first. If the regulator imposed the same standard anyway, both firms' profits would fall due to the increased price competition. Because the regulator cares about profits, however, it weakens the MQS in response to the high-quality firm's positioning, although the reduction in the MQS is less than one for one. While the restricted range of qualities that results intensifies price competition, the cost savings from reduced quality more than make up for any revenue lost from lower prices, and the firms enjoy increased profits relative to the benchmark case. The reduction in prices is not sufficient to compensate consumers for the loss in quality, however, and total welfare falls relative to the simultaneous-move case.

Given the results of the two preceding propositions we can compare directly the two Stackelberg equilibria discussed above.

Proposition 3. The equilibrium in the sequential game in which the high-quality firm chooses its quality level prior to the regulator's choice of 
the MQS features lower levels of quality, higher profits for the high-quality firm and a lower level of social welfare than the equilibrium of the sequential game in which the MQS is set first.

Proof. The proof follows directly from propositions 1 and 2. Q.E.D.

Our overall argument can be seen geometrically, as illustrated in Figure 2. Note first that the regulator's best response function $v\left(s_{H}\right)$ lies to the right of firm L's best response $k_{L}\left(s_{H}\right)$, indicating that social welfare maximization calls for higher quality than does firm L's profit-maximizing calculation. (This follows because firm L ignores externalities and also prefers excessively low quality as a way to mitigate price competition.) If the regulator promulgates standards before firm $\mathrm{H}$ sets its quality level, it will choose the point $\mathrm{R}$ at which firm H's best response is tangent to the best feasible iso-welfare curve, which is labeled $W^{\prime}\left(s_{H}, s_{L}\right)$. The regulator's most preferred point $\boldsymbol{s}^{*}$ is not attainable, given firm H's reaction. Point $\mathrm{R}$ involves higher quality on the part of both firms than would the simultaneous-move equilibrium where the regulator and the high-quality firm choose quality levels simultaneously but independently. Conversely, if the high-quality firm moves first, it chooses the point $\mathrm{H}$ where the regulator's best response function is tangent to the highest feasible isoprofit curve for firm $\mathrm{H}$, which is labeled $\pi_{H}^{\prime}\left(s_{H}, s_{L}\right)$. This involves lower

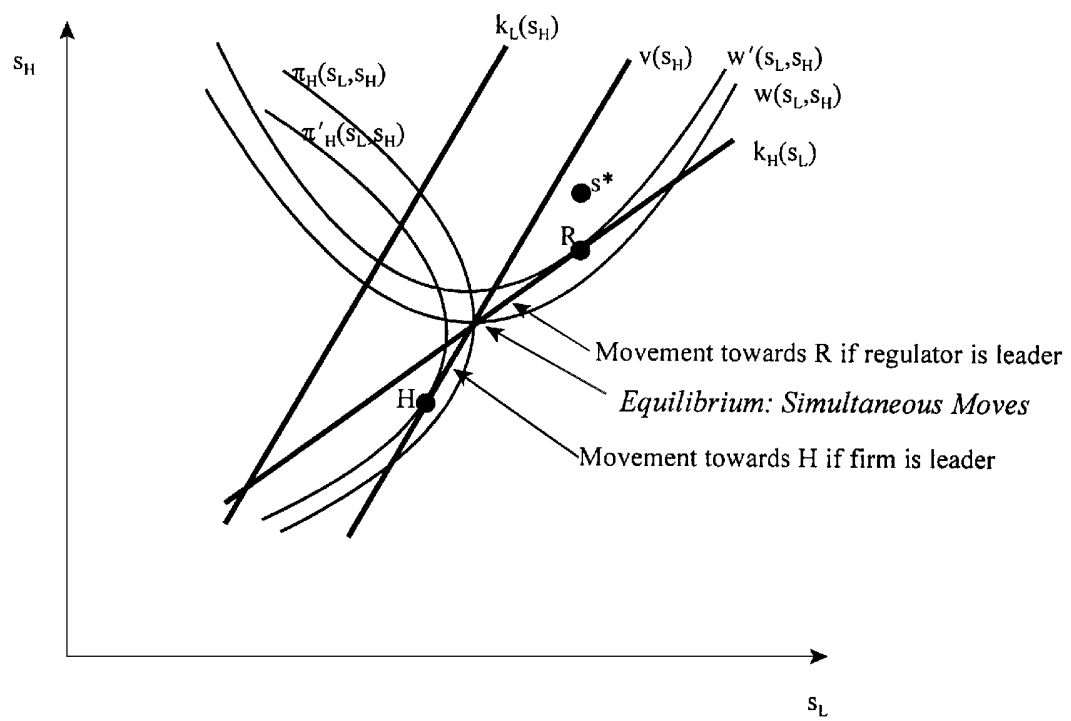

Figure 2

Equilibria for Different First Movers

(c) Blackwell Publishers Ltd. 2000. 
qualities for both firms than the simultaneous-move outcome, and $a$ fortiori, lower qualities than if the regulator had moved first. ${ }^{21}$

Propositions 1-3 illustrate that by clever strategic positioning, the high-quality leader can lower the quality 'ceiling' below which the regulator must operate, thereby mitigating the impacts of the regulation on corporate profits. As mentioned earlier, such positioning requires that the high-quality firm commit to a quality level and not re-adjust the 'quality frontier' of products on offer after the imposition of a standard. Interestingly, this appears to have been the case for appliance efficiency standards, as the technological frontier did not shift outward in the wake of the imposition of the standards. Of course, the overall effect on welfare of the reduced quality levels must be balanced against the sharper price competition that results when product differentiation is diminished. In our model, however, the net effects of the high-quality firm's strategic move are negative both for consumers and for social welfare in general.

It is important to note that our results are not driven by the precise specification of the regulator's objective function. Even if the regulator weights profits less than consumer surplus, our results still hold as long as the weight on profits remains strictly positive. The same type of results would emerge, for example, in a model where the regulator is driven by interest group pressures rather than pure welfare maximization.

\section{VERTICAL PRODUCT DIFFERENTIATION}

In this section, we study a specific model of duopolistic competition with endogenous (vertical) product qualities, and show that it satisfies the sufficient conditions identified in Section II. ${ }^{22}$ (For details on the calculations in this section, see the Supplementary Materials section of the Journal's editorial website.) Consumers have identical preferences, but income differences lead to differences in the willingness to pay for a particular product quality. Two firms offer products of different qualities in one market. The firms bear convex quality-dependent fixed costs and compete in qualities and prices in a two-stage industry game. Since greater product differentiation reduces substitutability and price competition, even firms with identical cost functions will offer distinct qualities in the resulting market equilibrium.

\footnotetext{
${ }^{21}$ Note the possibility that the regulator's ideal point may occur where the high-quality firm's profits are driven negative. In this case the regulator may set a MQS that is below its desired outcome, but still above the Nash, or lump sum transfers may be used to implement the desired MQS.

${ }^{22}$ Key papers in this line of research include Gabszewicz and Thisse [1979], Shaked and Sutton [1982], and Ronnen [1991]. 
In the standard version of this model, the consumption of a particular product of a certain quality only affects the utility of the individual consumer. Products involving safety, efficiency, or environmental standards, however, typically create at least some external impacts. Accordingly, we build a model in which an individual consumer internalizes some but not all of the benefits of higher quality, and we explicitly model the external effects of firms' quality choices. ${ }^{23}$ It is worth noting that while the model of this section is a special case of the model presented in Section II, the explicit inclusion of externalities makes it more general than much of the existing literature on vertical product differentiation, e.g. Ronnen [1991] or Arora and Gangopadhyay [1995].

\section{III(i). The Model}

There are two firms, the high-quality firm $\mathrm{H}$ and the low-quality firm L. If both firms remain in the market, then they produce distinct goods, sold at prices $p_{H}$ and $p_{L}$, respectively. The two products carry a single quality attribute denoted by $s_{H}$ and $s_{L}$, respectively. Sales quantities are given by $q_{H}$ and $q_{L}$. Each firm faces a fixed cost $F_{i}=b_{i} s_{i}^{2}, i=\{H, L\}$. We assume that $b_{L} \geq b_{H}$, that is, the firm which chooses to produce the higher quality product faces per-unit quality costs that are no greater than those faced by its rival. ${ }^{24}$ Marginal production costs are equal to zero for both firms.

There is a continuum of consumers (indexed by $t$ ) distributed uniformly over the interval $[0, \mathrm{~T}]$ with unit density. ${ }^{25}$ Each consumer purchases at most one unit of either firm H's product or firm L's product. The higher a consumer's income parameter $t$, the higher is her (his) reservation price. Consumer $t$ 's utility is given by $u_{t}=s_{i} t-p_{i}$ if good $i$ is purchased.

The two firms play a two-stage game. In the first stage, firms determine qualities to be produced and incur costs $F_{i}(i=H, L)$; these choices may be constrained by a minimum quality standard (MQS) imposed by the regu-

\footnotetext{
${ }^{23}$ For a pure public good, consumers derive no private benefit from purchasing a highquality product and individual firms derive no private benefit from quality leadership. Firms' only rationale for self-regulation in this setting is the complete preemption of future regulations; this case is studied in Maxwell et al. [2000].

${ }^{24}$ One way to interpret our assumption that the high-quality firm can commit to a quality level is to assume the firm must incur cost $F_{i}$ for any change of quality $s_{i}$. This corresponds to the case in Williamson [1985], chapter 7, in which all advance costs are nonsalvageable.

${ }^{25}$ The parameter $t$ represents willingness to pay and increases with income. Let $U[0, T]$ be the uniform probability distribution. Then this distribution of consumers corresponds to $T^{*} U[0, T]$ with density $T^{*} 1 /(T-0)=1$ for all $t$, regardless of the upper bound $T$. The total mass of consumers representing population size is equal to $T$, while the average income parameter $T / 2$ represents per-capita income. The assumption of a uniform distribution of consumers is a common simplification used in product differentiation models. Other distributional assumptions (such as distributions with mass points of consumers at zero) are equally legitimate and may yield different results. However our intention here is simply to illustrate that voluntary actions can be welfare reducing.

(c) Blackwell Publishers Ltd. 2000.
} 
lator. In the second stage, firms choose prices simultaneously (Bertrand competition). ${ }^{26}$ While we begin our exposition in this section with the unregulated equilibrium, it should be clear that our main interest is in quality choices when the regulator enforces an MQS, as discussed in Section II. As we will show, the MQS will be binding for the low-quality firm, so the game is effectively between the regulator and the high-quality firm. The interpretation of quality as the inverse of an index of environmental pollution is simple. Let pollution per unit of good $i$ be $1 / s_{i}$. Pollution per total quantity consumed of good $i$ is then $D_{i}=q_{i} / s_{i}$, and total pollution is given by $D=D_{H}+D_{L}$.

\section{III(ii). The Unregulated Equilibrium}

Despite the introduction of externalities, the equilibrium of the unregulated model is identical to that of Ronnen [1991] and Lehmann-Grube [1997], so in this section we simply record some of its key properties. It is straightforward to solve for the second-stage pricing equilibrium. Given this price equilibrium, demands and thus profits can be expressed in reduced form as functions of qualities. For positive qualities $s_{i}(i=H, L)$, these profit functions are:

$$
\Pi_{H}=\frac{4 T^{2} s_{H}^{2}\left(s_{H}-s_{L}\right)}{\left(4 s_{H}-s_{L}\right)^{2}}-b_{H} s_{H}^{2} \quad \Pi_{L}=\frac{T^{2} s_{H} s_{L}\left(s_{H}-s_{L}\right)}{\left(4 s_{H}-s_{L}\right)^{2}}-b_{L} s_{L}^{2} .
$$

Similarly, consumer surplus, and environmental degradation costs can be expressed in the following way:

$$
C S=\frac{T^{2} s_{H}^{2}\left(4 s_{H}+5 s_{L}\right)}{2\left(4 s_{H}-s_{L}\right)^{2}} \quad D=\frac{T\left(2 s_{L}+s_{H}\right)}{s_{L}\left(4 s_{H}-s_{L}\right)}
$$

Total welfare, $W$, is the sum of profits and consumer surplus, less environmental degradation costs.

From the properties of the profit functions, it can be shown that the two firms' qualities are strategic complements, as pictured in Figure 1. This is easy to understand for high-quality firm H: when firm L's quality improves, $\mathrm{H}$ has incentives to raise its quality further in order to maintain product differentiation and the relaxed price competition it provides. The upward slope of firm L's reaction curve has a slightly different explanation. One might expect that when firm $\mathrm{H}$ increases quality, firm $\mathrm{L}$ would not respond at all, enjoying the increased product differentiation. This is

\footnotetext{
${ }^{26}$ To derive solutions, we use the concept of subgame-perfect equilibrium, computing the solutions for each stage in reverse order. Both firms choose their respective product quality from the same interval $[0, \infty)$. The resulting market equilibria will include some consumers in the lower segment of the interval $[0, T]$ not valuing quality enough to buy any product. This guarantees an interior solution of the price game. 
incorrect, however; the marginal revenue to $\mathrm{L}$ of a quality increase is rising with $s_{H}$. When $\mathrm{H}$ raises his quality, this relaxes price competition and allows L's price to rise. The higher margin, in turn, makes it worthwhile to raise quality in order to expand demand. Hence firm L follows an increase in quality by firm $\mathrm{H}$, although at a rate less than one for one.

The regulator, of course, takes a broader view than do the firms, and includes consumer surplus and external costs in its objective function, as well as the firms' profits. Since the low-quality firm is interested only in profit maximization, the assumed distribution of consumers implies that the low-quality firm will always want to choose a lower quality level than the MQS. Hence, the regulator's reaction curve lies to the right of the lowquality firm's reaction curve, and the MQS chosen by the regulator will always be binding on the low quality firm. We show in Lemma 1 below that the regulator's reaction curve is also upward sloping.

\section{III(iii). The Sufficient Conditions for our Results}

In this section we show that the sufficient conditions identified in Section II hold in the specific case of our model of vertical product differentiation with externalities. It is straightforward to show that the high-quality firm's profits are globally concave in qualities. In addition, this firm's revenues are declining in $s_{L}$, and the cross-partial derivative of the high-quality firm's revenue function is positive. Global concavity of the social welfare function requires that the corresponding Hessian matrix of second derivatives of the welfare function be negative definite. This condition is straightforward, if somewhat tedious, to establish. The slope of the reaction functions, and the existence of an equilibrium when the regulator and firm $\mathrm{H}$ move simultaneously, are established in the following lemma.

Lemma 1. The regulator has an MQS best response function $v\left(s_{H}\right)$ with $v^{\prime}\left(s_{H}\right)>0$. An equilibrium exists in the simultaneous-move game in which the regulator sets an MQS that is binding on the low quality firm and firm $\mathrm{H}$ chooses its own quality.

Proof. The proof technique follows closely that of Lemma 1 in Lehmann-Grube [1997], and is omitted here.

Lemma 1 establishes the existence of the simultaneous-move equilibrium and the sign of the regulator's reaction function; as in Section II, we denote this equilibrium by $\boldsymbol{s}^{N}=\left(s_{L}^{N}, s_{H}^{N}\right)$. We turn now to a comparison of the welfare maximum $s^{*}$ and the Nash equilibrium $s^{N}$, as presented in the following lemma.

Lemma 2. Relative to the Nash equilibrium, $\boldsymbol{s}^{N}$, the welfare maximum is attained at a point $\boldsymbol{s}^{*}>\boldsymbol{s}^{N}$.

(c) Blackwell Publishers Ltd. 2000. 
Proof sketch. The regulator cares about consumer surplus, environmental damages, and the low-quality firm's profits, in addition to the highquality firm's profits. It can be shown that the sum of the first three of these is increasing in $s_{H}$, so $s_{H}^{*}>s_{H}^{N}$. Lemma 1 shows that $v^{\prime}\left(s_{H}\right)>0$. Hence $s_{L}^{*}>s_{L}^{N}$, and we have $\boldsymbol{s}^{*}>\boldsymbol{s}^{N}$.

We have now established that the assumptions made in Section II of the paper are satisfied in the particular case of a vertical product quality model with externalities and minimum quality regulation. Hence the results derived there apply here. While the model analyzed in this section is in a sense a 'special case', it is of interest for two significant reasons. First, it demonstrates by example that the assumptions made in Section II are general enough to encompass economically meaningful models. Second, it extends the existing literature on vertical product differentiation by explicitly incorporating external costs.

\section{DISCUSSION AND CONCLUSIONS}

We have presented a model in which firms have incentives to engage in proactive quality improvements in order to mitigate the impacts of forthcoming regulatory standards. By strategically sinking the costs of a technology that exceeds anticipated government standards by a limited amount, the leader influences the government to set a lower minimum quality standard. In our model, such proactive measures increase profits but reduce total social welfare. While this result is dependent on the underlying assumptions of the model, including upward-sloping reaction functions and an influential quality leader, it provides a new, and rather disquieting, perspective on the growing popularity of corporate environmental management activities.

Our analysis implies that the sometimes substantial delays in standard setting which follow Congressional directives can be damaging to welfare. As outlined in the Introduction, the delays in setting minimum efficiency standards for air conditioners and water heaters came to almost three years, while delays for new NESHAP requirements under the Clean Air Act Amendments stretched to a decade, and delays for effluent guidelines required by the Clean Water Act were even longer. Delays of these magnitudes allow industry leaders ample time to reposition their products and affect the final minimum quality standard. While some delays are unavoidable, our results imply that better results may be expected when regulatory agencies have ample staff and funding to allow them to implement new laws rapidly and without undue resource constraints. In addition, our analysis suggests that consumer and environmental groups may want to take a cautious view of seemingly beneficent corporate quality leadership, 
and may benefit from working to expedite the timely implementation of new standards.

Our results suggest there is a big difference between the welfare effects of corporate quality leadership that preempts mandatory regulations, and leadership that shapes regulations that cannot be preempted. As mentioned above, several recent papers find that preemptive self-regulation can have socially beneficial effects because it eliminates the transaction costs of using the regulatory process. Once new standards have been legislatively mandated, however, these costs can no longer be avoided, and the socially detrimental concerns raised in this paper come to the fore. A model that synthesizes these two possibilities may be an interesting topic for future research.

Another extension that may be worth investigating is the impact of asymmetric information in our model. If the regulator is uncertain of the cost of quality enhancements, then voluntary environmental improvements could signal to the regulator that the cost of quality is not too high, and might thus encourage the regulator to set more stringent standards. Since a tougher standard reduces the profits of both firms, the fear of triggering tougher standards would weaken the high-quality firm's incentive to undertake voluntary environmental improvement, cutting against the motivations we have examined here and perhaps discouraging the firm from taking voluntary actions. In the end, however, our aim here has not been to predict whether quality leadership would occur, but simply to assess the welfare implications when quality leadership is observed, as in the examples we cite at the beginning of the paper.

\section{REFERENCES}

Arora, S. and Gangopadhyay, S., 1995, 'Toward a Theoretical Model of Voluntary Overcompliance', Journal of Economic Behavior and Organization, 28, pp. 289-309.

Boom, A., 1995, 'Asymmetric International Minimum Quality Standards and Vertical Differentiation', Journal of Industrial Economics, 43, pp. 101-119.

Caulkins, P. and Sessions, S., 1997, 'Water Pollution and the Organic Chemicals Industry', in Morgenstern, R. D. (ed.), Economic Analysis at EPA: Assessing Regulatory Impact, Resources for the Future, Washington, DC.

Crampes, C. and Hollander, A., 1995, 'Duopoly and Quality Standards', European Economic Review, 39, pp. 71-82.

Gabszewicz, J. J. and Thisse, J.-F., 1979, 'Price Competition, Quality and Income Disparities', Journal of Economic Theory, 20, pp. 340-359.

Hansen, L. G., 1999, 'Environmental Regulation through Voluntary Agreements', in Carraro, C. and Lévêque, F. (eds.), Voluntary Approaches in Environmental Policy, Kluwer, Norwell, MA.

Hoffman, A., 1997, From Heresy to Dogma: An Institutional History of Corporate Environmentalism, New Lexington Press, San Francisco.

Khanna, M. and Damon, L., 1999, 'EPA's Voluntary 33/50 Program: Impact on Toxic Releases and Economic Performance of Firms', Journal of Environmental Economics and Management, 37, pp. 1-25.

(c) Blackwell Publishers Ltd. 2000. 
Lehmann-Grube, U., 1997, 'Strategic Choice of Quality When Quality is Costly: The Persistence of the High-Quality Advantage', RAND Journal of Economics, 28 , pp. 372-384.

Lévêque, F. and Nadaï, A., 1995, 'A Firm's Involvement in the Policy-Making Process', in Folmer, H., Gabel, H. L. and Opschoor, H. (eds.), Principles of Environmental and Resource Economics, Edward Elgar, Aldershot.

Linneman, P., 1980, 'The Effects of Consumer Safety Standards: The 1973 Mattress Flammability Standard', Journal of Law and Economics, 23, pp. 461-479.

Lyon, T. P. and Maxwell, J. W., 2000, 'Voluntary Approaches to Environmental Regulation', in Franzini, M. and Nicita, A. (eds.), Economic Institutions and Environmental Policy, Ashgate Publishing, Aldershot, forthcoming.

Maxwell, J. W., Lyon, T. P. and Hackett, S. C., 2000, 'Self-Regulation and Social Welfare: The Political Economy of Corporate Environmentalism', Journal of Law and Economics, forthcoming.

Newell, R. G., Jaffe, A. B. and Stavins, R. N., 1998, 'The Induced Innovation Hypothesis and Energy-Saving Technological Change', Resources for the Future, Washington, DC, Discussion paper 98-12.

Piasecki, B., 1992, 'Good Deeds and Good Numbers', Los Angeles Times, September 20, 1992.

Ronnen, U., 1991, 'Minimum Quality Standards, Fixed Costs, and Competition', Rand Journal of Economics, 22, pp. 490-504.

Schaefer, S., 1993, 'Cleaner Fuels for Competitive Advantage: ARCO and EC-1', Stanford Graduate School of Business, Case BE-10.

Segerson, K. and Miceli, T. J., 1998, 'Voluntary Environmental Agreements: Good or Bad News for Environmental Protection?', Journal of Environmental Economics and Management, 36, pp. 109-130.

Shaked, A. and Sutton, J., 1982, 'Relaxing Price Competition Through Product Differentiation', Review of Economic Studies, 49, pp. 3-13.

Stigler, G. J., (ed.), 1988, Chicago Studies in Political Economy, University of Chicago Press, Chicago, IL.

Viscusi, W. K., Vernon, J. M. and Harrington, J. E., Jr., 1995, Economics of Regulation and Antitrust, The MIT Press, Cambridge, MA.

Williamson, O. E., 1985, The Economic Institutions of Capitalism, The Free Press, New York. 